\title{
Analysis of the operation process of a training aircraft-Cessna 150
}

\author{
Marta Woch $^{1, *}$, Justyna Tomaszewska ${ }^{2, * *}$, Grzegorz Kamiński ${ }^{3, * * *}$, Kinga Kościak ${ }^{2, * * * *}$, Tomasz Zienkiewicz ${ }^{2, \dagger}$, Mariusz \\ Michalski $^{2, \ddagger}$, and Mariusz Zieja ${ }^{1, \S}$ \\ ${ }^{1}$ Air Force Institute of Technology, Warsaw, Poland \\ ${ }^{2}$ Faculty of Aviation, Polish Air Force Academy, Dȩblin, Poland \\ ${ }^{3}$ Institute of Aeronautics and Applied Mechanics, Warsaw University of Technology, Warsaw, Poland
}

\begin{abstract}
The method of the stochastic Markov process used for the analysis of operation of a training aircraftCessna 150 was presented in the article. In this article, the time changing probability of readiness was determined on the basis of knowledge of the current aircraft operation. Markov stochastic processes have been used as a model to determine aircraft-Cessna 150 readiness for specific tasks. In order to determine the readiness, the probability of being in one of the investigated states is determined. The analysed states included: standby, pre-flight service, flight, interstate service, after-flight service and hangar service.
\end{abstract}

\section{Introduction}

The method of the stochastic Markov process used for the analysis of operation of a training aircraft-Cessna 150 was presented in the article. The Cessna 150 aircraft is a twoseat training and tourist aircraft. Production began at the Cessna Aircraft Company's factory in Wichita, Kansas in 1958. On the basis of it, a number of models were developed, which differ in terms of equipment. Due to its ease of piloting, Cessna 150 is still very popular plane used for tourist licenses training in Poland and the United States $[1,2]$.

The Cessna 150 aircraft is a high-wing aircraft with a fully metal, semi-corup structure. The plane is equipped with a three-wheel fixed undercarriage. Controlled front undercarriage is equipped with a hydraulic-air cushioned shank. What distinguishes this plane from others is the window on the rear side around the rear window [3-5].

Description and characteristics of selected dimensions:

- Wingspan: $10.11 \mathrm{~m}$

- Maximum length: $7.24 \mathrm{~m}$

- Maximum height: $2.63 \mathrm{~m}$ including signal lamp and bent chassis

- Chassis spacing: $2.31 \mathrm{~m}$

- Fixed pitch propeller diameter: $1.752 \mathrm{~m}$

- Wing area: $14.8 \mathrm{~m}^{2}[6,7]$.

\footnotetext{
*e-mail: marta.woch@itwl.pl

**e-mail: j.tomaszewska@law.mil.pl

***e-mail: gkaminski@meil.pw.edu.pl

****e-mail: kinga.kosciak07@gmail.com

†e-mail: t.zienkiewicz@law.mil.pl

‡e-mail: m.michalski@law.mil.pl

$\S_{\text {e-mail: mariusz.zieja@itwl.pl }}$
}

\section{Calculation methodology}

\subsection{Markov chains}

Among analytical methods based on the analysis of random processes, also called state space methods, the most frequently used are the methods of the Markov chains and processes, and recently the semi-Markov processes. They are based on the assumption that the tested object of random process fulfilling the property of the Markov process $[8,9]$.

The random process is called the Markov process, when for any finite sequence of moments and any real numbers there is an equality [10]:

$$
\begin{aligned}
& P\left[X\left(t_{n}\right)<x_{n} \mid X\left(t_{n-1}\right)=x_{n-1}, \ldots, X\left(t_{1}\right)=x_{1}\right]= \\
& =P\left[X\left(t_{n}\right)<x_{n} \mid X\left(t_{n-1}\right)=x_{n-1}\right]
\end{aligned}
$$

This relationship means that the conditional probability distribution of a random variable $X\left(t_{n}\right)$ depends solely on the probability distribution of one of the random variables $X\left(t_{n-1}\right)$. Properties of the Markov process at the moment of $t_{n}$ do not depend on the values that the process assumed at moments $t_{1}, t_{2}, \ldots, t_{n-2}$. The Markov process is therefore fully characterized by the conditional distribution [11-13]:

$$
F(s, t, x, y)=P[X(t)<x \mid X(s)=y], s<t
$$

or the total distribution of random vector $(X(s), X(t))$ with initial distribution $F(s, y)=P[X(s)<y]$.

In the analysis of Markov's processes, a function called the probability of transition is essential, which is defined for any moment $t$, state $s$ and for any number of real $y$ and any Borel set $\mathbf{B}$, in the following way [14, 15]:

$$
P(s, t, \mathrm{~B}, y)=P[X(t) \in \mathrm{B} \mid X(s)=y]
$$


In the case of the Markov process, the probability distributions of time in the states must be exponential. The exception is the calculation of asymptotic reliability indicates. In some cases it is also possible to transform the state space in such a way that non-explanatory probability distributions will be replaced by a sequence of exponential distributions.

\subsection{Smoluchowski-Chapman-Kolmogorov equation}

In practical applications, especially in reliability considerations, the most important part is performed by Markov's point processes defined on the range $T=\left\langle t_{0}, \infty\right)$ with the state space $S=0,1,2, \ldots[16,17]$. The realizations of the Markov point process are functions of fixed intervals and their graphs are stair line [18].

For a point process Markov probability of transition $[19,20]$ :

$$
p_{i j}(s, t)=P[X(t)=j \mid X(s)=i], t \geq s ; i, j=0,1,2, \ldots
$$

satisfy the relationships:

$$
p_{i j}(s, t)=\sum_{k=0}^{\infty} p_{i k}\left(s, t_{1}\right) p_{k j}\left(t_{1}, t\right),\left(s<t_{1}<t\right)
$$

known as Smoluchowski-Chapman-Kolmogorov equation. Moreover, for each $i(i=0,1,2, \ldots)$ there is an equation:

$$
\sum_{j=0}^{\infty} p_{i j}(s, t)=1
$$

Introducing functions $\lambda_{i j}(t)$ known as process transition intensities or transition rates:

$$
\lambda_{i j}(t)=\lim _{\Delta t \rightarrow 0} \frac{1}{\Delta t} p_{i j}(t, t+\Delta t) ; i, j=0,1,2, \ldots ; i \neq j
$$

the system of differential equations with variable coefficients is obtained [21, 22]:

$$
\begin{aligned}
& \forall i \in S: \frac{d P_{i}(t)}{d t}=\lambda_{i i}(t) P_{i}(t)+\sum_{\substack{j \in S \\
i \neq j}} \lambda_{j i}(t) P_{j}(t) \\
& \lambda_{i i}(t)=-\sum_{\substack{j \in S \\
i \neq j}} \lambda_{i j}(t)
\end{aligned}
$$

where:

$P_{i}(t)$ - the unconditional probability of the process remaining at time $t$ at state $i[5,23]$,

$\lambda_{i j}(t)$ - the transition rate of the process at $t$ from state $i$ to state $j$.

When the Mark process is homogeneous, the transition rate is independent of the time $\lambda_{i j}(t)=\lambda_{i j}=$ const.,$i \neq j$ and a system of differential equations with constant coefficients is obtained:

$$
\forall i \in S: \frac{d P_{i}(t)}{d t}=\lambda_{i i} P_{i}(t)+\sum_{\substack{j \in S \\ i \neq j}} \lambda_{j i} P_{j}(t)
$$

for which knowledge of initial probabilities $P_{i}(0), i \in S$ is needed [24].
The above system can be written in vector form, as [25-27]:

$$
\frac{d}{d t} \mathbf{P}(t)=\boldsymbol{\Lambda}^{T} \mathbf{P}(t)
$$

where:

$\mathbf{P}(t)=\left[P_{1}(t), P_{2}(t), \ldots, P_{m}(t)\right]_{m \times 1}$ - column vector of probabilities of process presence in particular states,

$$
\boldsymbol{\Lambda}=\left[\begin{array}{cccc}
-\sum_{j=2}^{m} \lambda_{1 j} & \lambda_{12} & \ldots & \lambda_{1 m} \\
\lambda_{21} & -\sum_{\substack{j=1 \\
j \neq 2}}^{m} \lambda_{2 j} & \ldots & \lambda_{2 m} \\
\vdots & \vdots & \ddots & \vdots \\
\lambda_{m 1} & \lambda_{m 2} & \ldots & -\sum_{j=1}^{m-1} \lambda_{m j}
\end{array}\right]-
$$

transition rate matrix,

$m$ - number of sets $S$ (number of process states).

The elements of the $\boldsymbol{\Lambda}=\left[\lambda_{i j}\right] ; i, j \in S$ transition rate matrix the following probabilistic interpretation may be given [28-30]:

$$
\begin{gathered}
\lambda_{i j} \cdot \Delta t+o(\Delta t)=p_{i j}(\Delta t) \\
1-\lambda_{i} \cdot \Delta t+o(\Delta t)=p_{i i}(\Delta t)
\end{gathered}
$$

where $\frac{o(\Delta t)}{\Delta t} \underset{\Delta t \rightarrow 0}{\longrightarrow} 0$.

The expected value of the random variable $T_{i j}$ can be understood as the average time of stay in the state $S_{i}$ before the state $S_{j}$. From equation (11), the estimator of parameter $\lambda$ from the sample can be calculated from the formula [31-33]:

$$
\begin{gathered}
\hat{\lambda}_{i j}=\frac{1}{E\left[T_{i}\right]} \cdot \hat{p}_{i j}=\frac{n_{i}}{\sum_{k=1}^{N} t_{i}^{(k)}} \frac{n_{i j}}{n_{i}} \\
\hat{p}_{i j}=\frac{n_{i j}}{n_{i}}
\end{gathered}
$$

where: $S_{j}$

$n_{i j}$ - number of transitions from the state $S_{i}$ to the state $n_{i}$ - number of outputs from the $S_{i}$ state,

$t_{i}{ }^{(k)}$ - time of the object being in the $S_{i}$ state for observation number $k$ from the sample.

\section{The operational state model}

The operation process is the transition of aircraft from one operating state to another [34]. The transition from state to state of the aircraft under operation can be illustrated, by a direct graph or as a zero-one matrix.

An aircraft may be in one of the states in the operation process:

- $S_{1}$ - standby state;

- $S_{2}$ - pre-flight service state;

- $S_{3}$ - flight state;

- $S_{4}$ - interstate service state;

- $S_{5}$ - after-flight service state;

- $S_{6}$ - hangar service state.

The states $S_{1}, S_{2}, S_{3}$ and $S_{4}$ are classified as readiness states. 


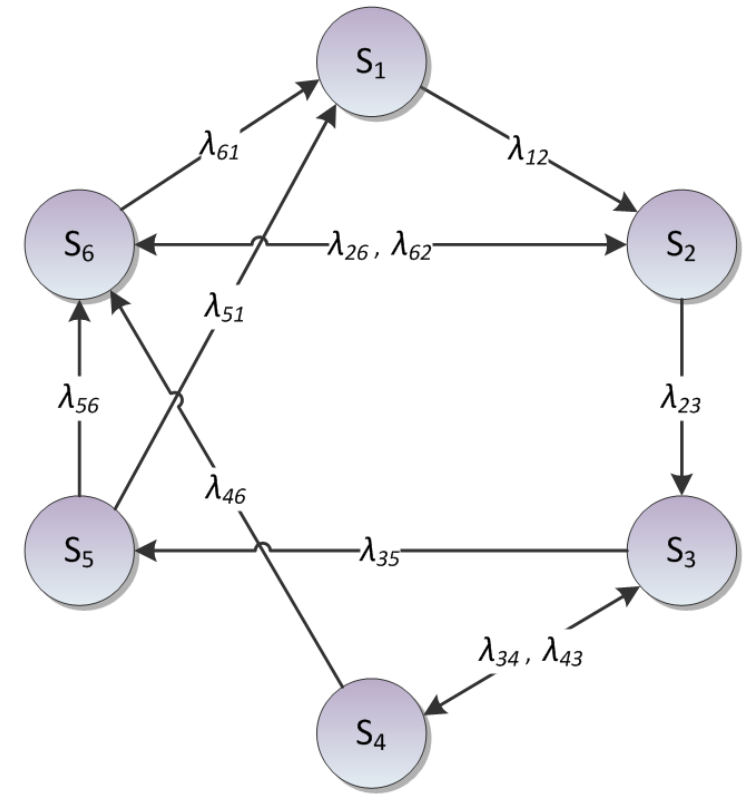

Figure 1. Directed graph of operating states of the Cessna 150 aircraft

Table 1. Number of flights performed at intervals assumed

\begin{tabular}{lcccc}
\hline Aircraft type & Day & Week & Month & Year \\
\hline Cessna 150 & 7 & 43 & 172 & 2009
\end{tabular}

Table 2. Average residence time of the aircraft in each state

\begin{tabular}{llr}
\hline No. & State & Time \\
\hline 1 & Standby & $8 \mathrm{~h}$ \\
\hline 2 & Pre-flight service & $40 \mathrm{~min}$ \\
\hline 3 & Flight & $90 \mathrm{~min}$ \\
\hline 4 & Interstate service & $22 \mathrm{~min}$ \\
\hline 5 & After-flight service & $35 \mathrm{~min}$ \\
\hline 6 & Hangar service & $8 \mathrm{~h}-24 \mathrm{~h}$ \\
\hline
\end{tabular}

Table 3. The probability of transition between individual operating states

\begin{tabular}{|c|c|c|c|c|c|c|}
\hline$p_{i j}$ & $S_{1}$ & $S_{2}$ & $S_{3}$ & $S_{4}$ & $S_{5}$ & $S_{6}$ \\
\hline$S_{1}$ & 0.000 & 0.975 & 0.000 & 0.000 & 0.000 & 0.025 \\
\hline$S_{2}$ & 0.000 & 0.000 & 0.975 & 0.000 & 0.000 & 0.025 \\
\hline$S_{3}$ & 0.000 & 0.000 & 0.000 & 0.699 & 0.301 & 0.000 \\
\hline$S_{4}$ & 0.000 & 0.000 & 0.996 & 0.000 & 0.000 & 0.004 \\
\hline$S_{5}$ & 0.975 & 0.000 & 0.000 & 0.000 & 0.000 & 0.025 \\
\hline$S_{6}$ & 1.000 & 0.000 & 0.000 & 0.000 & 0.000 & 0.000 \\
\hline
\end{tabular}

\section{Results}

On the basis of the collected data, the exploitation graph presented in Figure 1 was developed.

The number of flights performed at intervals assumed are presented in table 1 .

The average residence time of the aircraft in each state are presented in table 2 .
Table 4. The transition rates between individual operating states

\begin{tabular}{|c|c|c|c|c|c|c|}
\hline$\lambda_{i j}$ & $S_{1}$ & $S_{2}$ & $S_{3}$ & $S_{4}$ & $S_{5}$ & $S_{6}$ \\
\hline$S_{1}$ & -0.090 & 0.088 & 0.000 & 0.000 & 0.000 & 0.002 \\
\hline$S_{2}$ & 0.000 & -1.907 & 1.859 & 0.000 & 0.000 & 0,048 \\
\hline$S_{3}$ & 0.000 & 0.000 & -0.100 & 0.077 & 0.033 & 0.000 \\
\hline$S_{4}$ & 0.000 & 0.000 & 0.505 & -0.507 & 0.000 & 0.002 \\
\hline$S_{5}$ & 1.767 & 0.000 & 0.000 & 0.000 & -1.813 & 0.046 \\
\hline$S_{6}$ & 1.170 & 0.000 & 0.000 & 0.000 & 0.000 & -1.170 \\
\hline
\end{tabular}

The system shown in Figure 1 can be described by a system of differential equations [10]:

$$
\begin{aligned}
\frac{d P_{1}(t)}{d t}= & -\lambda_{12} P_{1}(t)+\lambda_{51} P_{5}(t)+\lambda_{61} P_{6}(t) \\
\frac{d P_{2}(t)}{d t}= & -\left(\lambda_{23}+\lambda_{26}\right) P_{2}(t)+\lambda_{12} P_{1}(t)+\lambda_{62} P_{6}(t) \\
\frac{d P_{3}(t)}{d t}= & -\left(\lambda_{34}+\lambda_{35}\right) P_{3}(t)+\lambda_{23} P_{2}(t)+\lambda_{43} P_{4}(t) \\
\frac{d P_{4}(t)}{d t}= & -\left(\lambda_{43}+\lambda_{46}\right) P_{4}(t)+\lambda_{34} P_{3}(t) \\
\frac{d P_{5}(t)}{d t}= & -\left(\lambda_{51}+\lambda_{56}\right) P_{5}(t)+\lambda_{35} P_{3}(t) \\
\frac{d P_{6}(t)}{d t}= & -\left(\lambda_{61}+\lambda_{62}\right) P_{6}(t)+\lambda_{26} P_{2}(t)+\lambda_{46} P_{4}(t) \\
& +\lambda_{56} P_{5}(t)
\end{aligned}
$$

where:

$P_{1}(t)$ - the probability that the system is in a standby state;

$P_{2}(t)$ - the probability that the system is in a pre-flight service state;

$P_{3}(t)$ - the probability that the system is in a flight state;

$P_{4}(t)$ - the probability that the system is in a interstate service state;

$P_{5}(t)$ - the probability that the system is in a after-flight service state;

$P_{6}(t)$ - the probability that the system is in a hangar service state.

These probabilities can be determined using the program Wolfram Mathematica.

\subsection{Analysis of the readiness of a Cessna 150 aircraft to perform a training task}

The probabilities of transition between individual operating states are presented in the table 3.

The transition rates between particular operating states are presented in the table 4.

Figure 2 shows the probabilities of being in one of the analysed operating states as a function of time, assuming that the initial state was the standby state.

On this basis, it can be observed that the probability that an aircraft of type Cessna 150 will remain in the standby state in the initial phase is $100 \%$ and decreases over time. After approximately 30 days, this probability reaches a constant level (known as the threshold probability) of approximately $23 \%$. The probability of an aircraft being in a flight condition increases within 30 days and has 


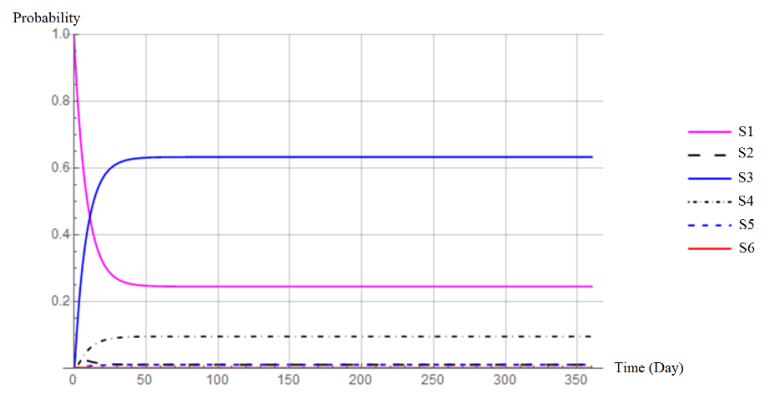

Figure 2. The transition rates between individual operating states

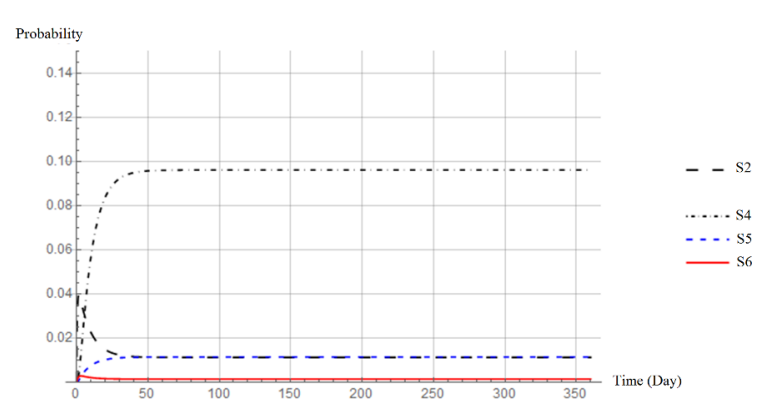

Figure 3. The transition rates between individual operating states

remained stable since then, at approximately $62 \%$. Probabilities for states with a lower value are shown in Figure 3. The probability of being in the interstate service state of approximately $9 \%$ has been obtained. It shows that the probability of the aircraft in the pre-flight service state is decreasing, while the probability of the aircraft in the afterflight service state is increasing. After approximately 30 days, these two probabilities converge and remain stable at $1 \%$. The probability that an aircraft is in the hangar service state is just over $0 \%$.

On the basis of the calculations, it can be seen that the results for the different initial states differ in the initial phase and are the same in the final phase. The presented probabilities reach a constant level of probability after 30 days, known as the limit probability.

The Cessna 150 aircraft rarely fails, provided that the proper maintenance is carried out regularly and that it is carried out in accordance with the manufacturer's instructions for use.

\section{Conclusions}

On the basis of the presented results, approximate probabilities of a Cessna 150 aircraft in the assumed operating states were determined. The results obtained differ in the initial phase depending on the assumed initial state. After about 30 days, the probabilities shown in the probability diagrams, reach constant levels called limit probabilities. It has been assumed that hangar service operations are performed regularly in accordance with the guidelines described by the manufacturer in the operating instructions.
In addition, it is assumed that operations are carried out correctly by appropriately trained personnel. It can be concluded that Cessna 150 aircraft rarely fail.

\section{References}

[1] Type certificate data sheet no. 3a19, http: //www . airweb. faa.gov/Regulatory_and_ Guidance_Library/rgMakeModel.nsf/0/ 9145d78f43cafe5e8625724300634b5e/\$FILE/ 3a19.pdf

[2] M. Hinz, Concept for Machine Learning and Field Data Driven Adjustment of Testing Conditions of Technical Prototypes, Berichte aus der Zuverlässigkeitsanalytik und Risikoforschung (Shaker Verlag, 2018), ISBN 9783844060225

[3] Instrukcja obstugi technicznej samolotu cessna 150l, http://www . aeroklub2 . home.pl/pliki/ cessna1501.pdf

[4] M. Hinz, F. Hienzsch, S. Bracke, Detection of Distinctions in Car Fleets Based on Measured and Simulated Data, in RAMS 2017-63rd Annual Reliability and Maintainability Symposium (Orlando, Florida, U.S.A., 2017)

[5] M. Koucky, D. Valis, Reliability of sequential systems with a restricted number of renewals, in Proceedings and Monographs in Engineering, Water and Earth Sciences 2007, edited by T. Aven, J.E. Vinnem (Stavanger, Norway, 2007), pp. 1845-1849

[6] C.A. Company, 150 series 1969 thru 1976 service manual, https://www.redskyventures.org/ doc/cessna-maintenance-manuals/Cessna_ 150_1969-1976_MM_D971-3-13.pdf

[7] Vališ, D. and Žák, L. and Pokora, O., Failure prediction of diesel engine based on occurrence of selected wear particles in oil, in Engineering Failure Analysis (2015), Vol. 56, pp. 501 - 511, the Sixth International Conference on Engineering Failure Analysis

[8] A.V. Kozyrev, V.Y. Kozhevnikov, N.S. Semeniuk, L.A. Zyulkova, Theoretical Simulation of a Gas Breakdown Initiated by External Plasma Source in the Gap With Combined Metal-Dielectric Electrodes, in IEEE Transactions on Plasma Science (2015), Vol. 43, No. 8, pp. 2294-2298, ISSN 0093-3813

[9] Z. Vintr, D. Valis, Modeling and Analysis of the Reliability of Systems with One-shot Items, in 2007 Annual Reliability and Maintainability Symposium (2007), pp. 380-385, ISSN 0149-144X

[10] A. Kalinska, A. Wojcik, J. Slosarz, B. Kruzinska, M. Michalczuk, S. Jaworski, M. Wierzbicki, M. Golebiewski, Occurrence and aetiology of Staphylococcal mastitis - a review, in Animal Science Papers and Reports (2018), Vol. 36, No. 3, pp. 263273

[11] D. Valis, Z. Vintr, Dependability of mechatronics systems in military vehicle design, in Proceedings and Monographs in Engineering, Water and Earth Sciences, SAFETY AND RELIABILITY FOR MANAGING RISK, European Safety and Reliability Con- 
ference (ESREL 2006) (Estoril, PORTUGAL, 2006), Vol. 1-3, pp. 1703-1707

[12] B. Babiarz, Aspects of Heat Supply Security Management Using Elements of Decision Theory, in Energies (2018), Vol. 11, No. 10, pp. 1-14, article Number: 2764

[13] Z. Vintr, D. Valis, A Tool for Decision Making in $K$ Out-of- $N$ System Maintenance, in Mechanical and Aerospace Engineering, ICMAE2011 (Trans Tech Publications, 2012), Vol. 110 of Applied Mechanics and Materials, pp. 5257-5264

[14] V.Y. Kozhevnikov, A.V. Kozyrev, N.S. Semeniuk, A.V. Batrakov, V.M. Karaban, D.S. Kosov, Design and diagnostics of arc-resistant electronics for satellite telecommunication systems, in 2016 18th Mediterranean Electrotechnical Conference (MELECON) (2016), pp. 1-5

[15] A. Mueller, M. Hinz, S. Bracke, Optimization of the dental implant testing based on FEM simulation of fatigue and accelerated life, in Risk, Reliability and Safety: Innovating Theory and Practice (Glasgow, Scotland, 2017), pp. 16-22, ESREL 2017

[16] F. Grabski, Semi-Markov Processes: Applications in System Reliability and Maintenance (Elsevier Science, 2014), ISBN 9780128005187

[17] F. Maturo, S. Hošková-Mayerová, Fuzzy regression models and alternative operations for economics and social sciences, in Recent Trends in Social Systems: Quantitative Theories and Qualitative Models (2017), Vol. 66 of Studies in Systems, Decision and Control, pp. 235-247

[18] L. Hynčík, T. Bońkowski, J. Vychytil, Virtual hybrid human body model for PTW safety assessment, in Applied and Computational Mechanics (2017), Vol. 11, No. 2, p. 137-144

[19] D. Valis, L. Zak, O. Pokora, Engine residual technical life estimation based on tribo data, in Eksploatacja i Niezawodnosc - Maintenance and Reliability (2014), Vol. 16, No. 2, pp. 203-210

[20] V.Y. Kozhevnikov, N. Semeniuk, A.V. Kozyrev, V.M. Karaban, D.S. Kosov, Novel automated software system for arcing simulation in spacecraft on-board electronics, in 2017 2nd International Conference on System Reliability and Safety (ICSRS) (2017), pp. 469-473

[21] B. Babiarz, Heat supply system reliability management, in Safety and Reliability: Methodology and Applications. Proc. of the European Safety and Reliability Conference, ESREL 2014, edited by e.a. Tomasz Nowakowski (CRC Press, 2015), pp. 513520

[22] L. Hynčík, T. Bońkowski, W. Lv, Development of a simple motorcyclist helmet finite element model, in International Journal of Vehicle Safety (2018), Vol. 10, No. 3/4, p. 277-287

[23] S. Hošková-Mayerová, Education and Training in Crisis Management, in The European Proceedings of Social E Behavioural Sciences EpSBS (2016), Vol.
XVI, pp. 849-856

[24] W. Lv, L. Hyncik, T. Bonkowski, Rider Stature Influence to Injury Risk in Motorcycle Rear Impact to Car, in Asia-Pacific Automotive Engineering Conference (SAE International, 2019), ISSN 0148-7191, https://doi .org/10.4271/2019-01-1436

[25] B. Babiarz, P. Kut, District heating simulation in the aspect of heat supply safety, in VI International Conference of Science and Technology INFRAEKO 2018. Modern cities. Infrastructure and Environmental (2018), Cracov, E3S Web of Conferences 45, 00005

[26] R. Urban, S. Hošková-Mayerová, Threat Life Cycle and Its Dynamics, in Deturope (2017), Vol. 9, pp. 93-109

[27] M. Adamski, W. Lorenc, J. Cwiklak, Vertical take off reconnaissance Unmanned Air Vehicle, in 2014 IEEE Chinese Guidance, Navigation and Control Conference (CGNCC) (2014), pp. 986-990

[28] R. Ocaña-Rilola, Two Methods To Estimate Homogenous Markov Processes, in Journal of Modern Applied Statistical Methods (2002), Vol. 1, No. 1, pp. 131-138, article 17

[29] J. Gajewski, D. Valis, The determination of combustion engine condition and reliability using oil analysis by MLP and RBF neural networks, in Tribology International (2017), Vol. 115, p. 557-572

[30] D. Tloczynski, Air Transport Service in Academic Research at Polish Airports, in Advances in Intelligent Systems and Computing, edited by G. Sierpinski (Katowice, Poland, 2017), Vol. 505, pp. 23-32, conference: 13th Scientific and Technical Conference on Transport Systems. Theory and Practice

[31] B. Babiarz, Resilience to hazards in district heating systems, in Safety and Reliability of Complex Engineered Systems: ESREL 2015, edited by e.a. Luca Podofillini (CRC Press/Balkema, 2015), pp. 2525-2531

[32] S. Bracke, M. Hinz, M. Inoue, E. Patelli, S. Kutz, H. Gottschalk, B. Ulutas, C. Hartl, P. Moers, P. Bonnaud, Reliability engineering in face of shorten product life cycles: Challenges, technique trends and method approaches to ensure product reliability, in Risk, Reliability and Safety: Innovating Theory and Practice, edited by Walls, L and Revie, M and Bedford, T (Glasgow, Scotland, 2017), pp. 2884-2891, ESREL 2017

[33] D. Tloczynski, Security as a determinant of choice of air transport service and air carrier on the basis of research, in Scientific Journal of Silesian University of Technology-Series Transport (2017), Vol. 95, pp. 213-222

[34] M. Hinz, F. Hienzsch, S. Bracke, Development of two methods for the characterisation of an automotive fleet behaviour based on the simulation of single car rides, in Risk, Reliability and Safety: Innovating Theory and Practice, edited by Walls, L and Revie, $\mathrm{M}$ and Bedford, T (Glasgow, Scotland, 2017), pp. 1593-1598, ESREL 2017 